\title{
Relative roles of local disturbance, current climate and paleoclimate in determining phylogenetic and functional diversity in Chinese forests
}

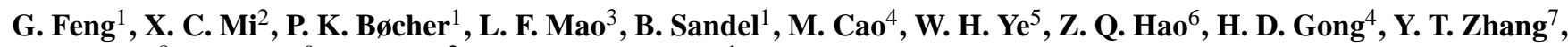 \\ X. H. Zhao ${ }^{8}$, G. Z. Jin ${ }^{9}$, K. P. $\mathrm{Ma}^{2}$, and J.-C. Svenning ${ }^{1}$ \\ ${ }^{1}$ Ecoinformatics and Biodiversity Group, Department of Bioscience, Aarhus University, Ny Munkegade 114, 8000 Aarhus C, \\ Denmark \\ ${ }^{2}$ State Key Laboratory of Vegetation and Environmental Change, Institute of Botany, Chinese Academy of Sciences, 20 \\ Nanxincun, Xiangshan, Beijing, 100093, China \\ ${ }^{3}$ Department of Plant Biology, Michigan State University, East Lansing, Michigan, 48824, USA \\ ${ }^{4}$ Key Laboratory of Tropical Forest Ecology, Xishuangbanna Tropical Botanical Garden, Chinese Academy of Sciences, \\ 650223, Kunming, China \\ ${ }^{5}$ Key Laboratory of Plant Resources Conservation and Sustainable Utilization, South China Botanical Garden, Chinese \\ Academy of Sciences, 510650, Guangzhou, China \\ ${ }^{6}$ State Key Laboratory of Forest and Soil Ecology, Institute of Applied Ecology, Chinese Academy of Sciences, P.O. Box 417, \\ 110016, Shenyang, China \\ ${ }^{7}$ Institute of Forest Ecology, Xinjiang Academy of Forestry, 830000, Urumqi, China \\ ${ }^{8}$ Key Laboratory for Forest Resources and Ecosystem Processes of Beijing, Beijing Forestry University, 100083, Beijing, \\ China \\ ${ }^{9}$ Center for Ecological Research, Northeast Forestry University, Harbin, 150040, China
}

Correspondence to: G. Feng (gang.feng@biology.au.dk)

Received: 12 July 2013 - Published in Biogeosciences Discuss.: 5 September 2013

Revised: 17 January 2014 - Accepted: 17 January 2014 - Published: 10 March 2014

\begin{abstract}
The main processes underlying the generation and maintenance of biodiversity include both local factors such as competition and abiotic filtering and regional forces such as paleoclimate, speciation and dispersal. While the effects of regional and local drivers on species diversity are increasingly studied, their relative importance for other aspects of diversity, notably phylogenetic and functional diversity is so far little studied. Here, we link data from large Chinese forest plots to data on current and Last Glacial Maximum (LGM) climate as well as local disturbance regimes to study their relative roles in determining woody plant phylogenetic and functional diversity in this important hotspot for woody plant diversity. Local disturbance was the best predictor of functional diversity as represented by maximum canopy height $\left(H_{\max }\right)$, probably reflecting the dominant role of competition for light in determining the for-
\end{abstract}

est $H_{\max }$ structure. In contrast, the LGM-present anomaly in temperature was the factor with the strongest explanatory power for phylogenetic diversity, with modern climate also important. Hence, local contemporary and regional historical factors have highly contrasting importance for the geographic patterns of the functional (as represented by variation in maximum canopy height) and phylogenetic aspects of Chinese forest's woody plant diversity. Importantly, contemporary factors are of overriding importance for functional diversity, while paleoclimate has left a strong signature in the phylogenetic diversity patterns. 


\section{Introduction}

How biodiversity is generated and maintained is a central issue in ecology (Ricklefs, 1987; Pennisi, 2005; De Aguiar et al., 2009; Tittensor et al., 2010). Traditionally, emphasis has been on local forces such as competition, abiotic filtering and predation (Chesson, 2000; Svenning et al., 2004; Chen et al., 2010), but historical factors (e.g., paleoclimate) and related regional processes (speciation, extinction and dispersal) are increasingly also considered (Dynesius and Jansson, 2000; Sandel et al., 2011; Kissling et al., 2012).

Many studies have considered the roles of local factors in determining diversity and structure in tropical, subtropical, and temperate forests (Svenning et al., 2004; Chen et al., 2010; Zhu et al., 2010; Wang et al., 2011). For instance, in one tropical forest, spatial location, environmental factors and past land use were all found to have important impacts on species composition (Svenning et al., 2004). Moreover, strong effects of current climate have been found in studies spanning larger geographic extents (Wang et al., 2009a, b). At such scales important imprints of historical regional factors have also been found (Latham and Ricklefs, 1993; Ricklefs et al., 1999; Greve et al., 2011; Kissling et al., 2012; Rakotoarinivo et al., 2013).

However, these studies mainly focused on species richness, which ignores ecological and evolutionary differences among species. During the past decade, forest ecologists have increasingly used phylogenetic and functional information to provide novel insights into studies on community ecology (Webb et al., 2002; Kunstler et al., 2012; Mi et al., 2012; Swenson, 2013). Overall, phylogenetic patterns should reflect the imprints of evolutionary and biogeographic history on community structure (Kellermann et al., 2012a; Kellermann et al., 2012b; Kissling et al., 2012). In contrast, functional traits should be directly linked to ongoing ecological processes (Swenson, 2013), while phylogenetic patterns would only indirectly (via niche conservatism) or not (Purschke et al., 2013) relate to these.

China is a global hotspot for plant diversity (López-Pujol et al., 2006) and harbors a broad range of forest types (Qian and Ricklefs, 1999); its temperate forests are the most diverse on Earth (Qian and Ricklefs, 2000). The high species richness has been attributed to high levels of topographic heterogeneity, strong connectivity to the tropics, and more stable paleoclimate with less influence of the Pleistocene glaciations than in other temperate areas such as much of North America (Qian and Ricklefs, 1999, 2000). Previous studies have investigated woody plant species richness patterns in forests across China and did find important roles of both current and historical factors (Qian and Ricklefs, 1999; Wang et al., 2009b). However, large-scale variations in phylogenetic and functional woody plant community structure across China have hitherto remained unstudied, but are the focus of the present study. Overall, one may predict that phylogenetic structure should primarily reflect current or paleocli- mate via climatic niche conservatism (Wiens and Graham, 2005; Losos, 2008) or paleoclimatic effects on diversification (Dynesius and Jansson, 2000). Climatic niche conservatism may also result in paleoclimatic effects via dispersallagged climate-change-induced range dynamics (Hortal et al., 2011). In contrast, functional community structure may be more strongly related to contemporary ecological processes, e.g., succession (Purschke et al., 2013).

Additionally, assembly mechanisms may differ among organisms due to differences in dispersal ability or other functional traits (Sandel et al., 2011; Lindström and Langenheder, 2012). In northeastern China, tree species richness was found to be mainly constrained by climate, while shrub richness was more correlated to local factors (Wang et al., 2009a). Therefore, trees and shrubs may also exhibit different phylogenetic and functional patterns across Chinese forests, but this has so far not been studied.

Here, we linked data on woody plant communities in Chinese forests to data on local disturbance (representing successional dynamics), current climate, and paleoclimate (climate shifts between the LGM and now) to assess their relative roles in determining functional and phylogenetic diversity in these ecosystems. We also tested if these relations differed between the two main growth forms: trees and shrubs.

\section{Material and methods}

\subsection{Data}

\subsubsection{Forest communities}

Forest community data was mainly collected from the Chinese Forest Biodiversity Monitoring Network (CForBio, http://www.cfbiodiv.org), which aims to study mechanisms underlying biodiversity and community structure in Chinese forests, with additional data from other published studies. In total, data were included from 11 forest plots across China (Table A1, Fig. 1). The plots were located in forest types ranging from temperate forests to subtropical and tropical forests, spanning tree diversities from 8 to 342 woody species. Generally, plots in southern China have more precipitation and more complex topographic variation (Table A1; Qian and Ricklefs, 1999). All woody individuals with diameter at breast height $(\mathrm{DBH}) \geq 1 \mathrm{~cm}$ were measured and identified to species when possible. Here, we used the species list and species abundance data from each plot, representing a total of 1102 species and 495815 individuals, among which gymnosperms constitute 16 species and 23940 individuals.

\subsubsection{Phylogenetic tree}

A phylogenetic tree (see Supplement) including the 1102 species was constructed by the plant phylogeny database Phylomatic (Webb and Donoghue, 2005), which uses the Angiosperm Phylogeny Group III (2009) classification. The 


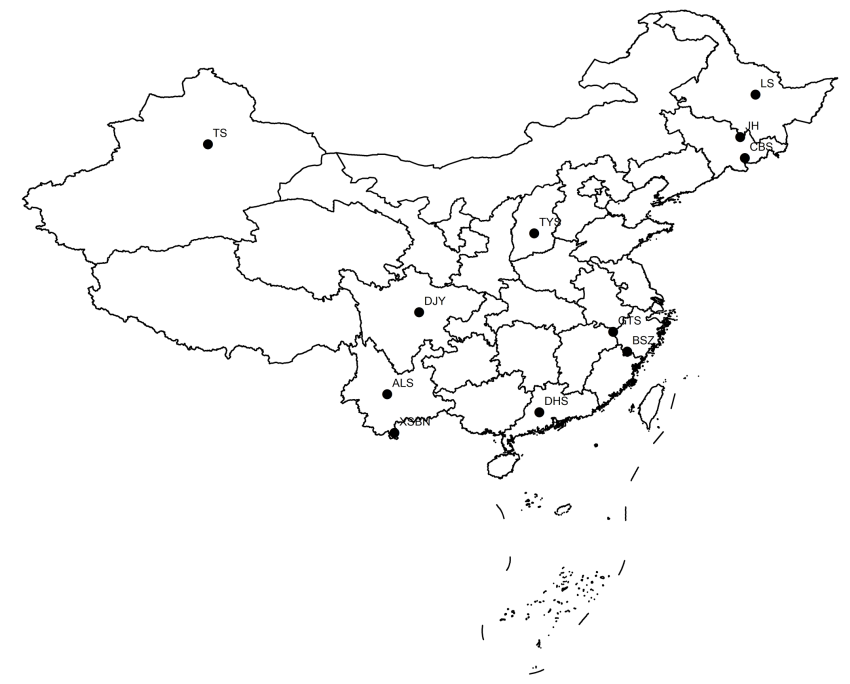

Fig. 1. Locations of the 11 forest plots: Liangshui (LS), Jiaohe (JH), Changbaishan (CBS), Taiyueshan (TYS), Dujiangyan (DJY), Ailaoshan (ALS), Xishuangbanna (XSBN), Dinghushan (DHS), Gutianshan (GTS), Baishanzu (BSZ).

BLADJ (branch length adjustment) algorithm was used to estimate phylogenetic branch lengths using Phylocom 4.1 (Webb et al., 2008). To investigate the difference between trees and shrubs, we also built two phylogenetic trees using the same method, with one including 570 species of trees and the other including 167 species of shrubs (365 spp. without a clear growth form assignment). Species-level information on growth form (shrub or tree) came from Flora of China (http://www.efloras.org/).

\subsubsection{Functional trait data}

Functional community structure was computed based on a single functional trait of key importance in plant communities, maximum canopy height $\left(H_{\max }\right)$. Other traits, such as seed size, wood density, leaf related traits, are also important for plant communities, but $H_{\max }$ was the only trait broadly available for the study species; $H_{\max }$ of each species was recorded from Flora of China, and, in total, we found $H_{\max }$ information for 958 species $(n=559$ tree spp., 161 shrub spp. and 238 spp. without a clear growth form assignment). A similarity distance matrix for $H_{\max }$ of all species was then constructed, comparing the $H_{\max }$ values for all pairs of species using Euclidian distance. Subsequently, we conducted a cluster analysis (complete linkage method that finds similar clusters) of this distance matrix and constructed a dendrogram (see Supplement) based on the results of cluster analysis. Finally, two similar functional trees were computed just for trees and shrubs.

\subsubsection{Environmental data}

Data on current climate came from the WorldClim database (Hijmans et al., 2005). Here, we considered mean annual temperature (MAT), maximum temperature of warmest month (MTWM), minimum temperature of coldest month (MTCM), mean annual precipitation (MAP), precipitation of wettest month (PWM) and precipitation of driest month (PDM). We used the finest-resolution current climate layers available, i.e., $0.00833^{\circ}$. We represented paleoclimate factors using the MAT anomaly (present-day MAT from Worldclim - LGM MAT from a paleoclimate model) and the velocity of MAT (the ratio of the temporal MAT gradient to the spatial MAT gradient, Loarie et al., 2009; Sandel et al., 2011). Both used the mean of the Community Climate System Model version 3 (CCSM3) and Model for Interdisciplinary Research on Climate version 3.2 (MIROC3.2) paleoclimatic simulations for the Last Glacial Maximum (LGM, 0.021 Mya). CCSM3 is a coupled climate model, which has components representing the atmosphere, ocean, sea ice and land surface connected by a flux coupler (Collins et al., 2006). MIROC 3.2 includes a T42 global atmospheric spectral model and a medium-resolution ocean model (K-1 Model Developers, 2004). Both of these models have been widely used in recent macroecological studies (Sandel et al., 2011; Kissling et al., 2012; Rakotoarinivo et al., 2013; Smith et al., 2013). The CCSM3 model had an initial resolution of $1.4^{\circ}$ at the Equator, and the MIROC3.2 has a resolution of $2.8125^{\circ}$. These estimates were provided by WorldClim calibrated and statistically downscaled to a resolution of $0.04167^{\circ}$ using the WorldClim data for current climate (http://www.worldclim.org/past). All climate variables were processed in ArcMap 10.1.

Local disturbance (disturbances in these plots were mainly natural disturbances, such as natural fires, typhoons and ice storms, as all the plots were built in core areas of natural reserves or natural forests) was presented by the proportion of light-demanding species (LDSR) (Molino and Sabatier, 2001). Species were scored as light-demanding ( $n=346$ spp.) primarily based on their habitat descriptions (occurrence in open forest or in disturbed, anthropogenic habitats) in Flora of China (Feng et al., 2014). Finally, to account for the varying plot areas (Table A1), plot area was also included as an explanatory variable in the modeling.

\subsection{Methods}

The net relatedness index (NRI) (Webb et al., 2002) was used to quantify phylogenetic community structure (NRI $\mathrm{PHY}_{\mathrm{P}}$ ). The formula is

$\mathrm{NRI}=-1 \times \frac{\mathrm{MPD}_{\mathrm{obs}}-\text { meanMPD }_{\text {rnd }}}{\mathrm{sdMPD}_{\text {rnd }}}$,

where $\mathrm{MPD}_{\mathrm{obs}}$ is the observed mean phylogenetic distance (MPD) of a plot, meanMPD ${ }_{\text {rnd }}$ is the mean MPD of the 
null models (shuffle distance matrix labels), and sdMPD $\mathrm{Pnd}_{\text {rnd }}$ is the standard deviation (SD) of MPD of the null models. MPD mainly reflects the deep phylogenetic structure in a phylogeny. In other words, MPD is usually thought to be more sensitive to the tree-wide patterns of phylogenetic overdispersing or clustering (Webb et al., 2002; Swenson, 2009) than to the structure near the tips. As the deeper parts of the phylogeny used are well supported, coming from Angiosperm Phylogeny Group III classification, there should not be any important bias in NRI measures caused by the limited tip resolution in the phylogeny used. Functional diversity was calculated in the same way as NRI (Swenson and Enquist, 2009), but using the functional $H_{\max }$-based dendrogram described above (NRI $\mathrm{FUN}_{\mathrm{FU}}$ ). Both abundance weighted and presence-absence based NRI $\mathrm{PHY}_{\mathrm{PH}}$ and $\mathrm{NRI}_{\mathrm{FUN}}$ were computed (indicated by _ab and_pr subscripts). As phylogenetic outliers may strongly influence phylogenetic community structure (Letcher et al., 2012; Feng et al., 2014), NRI $_{\text {PHY }}$ was furthermore computed including both gymnosperms and angiosperms or only angiosperms (indicated by _gym and_ang subscripts).

To avoid including large numbers of correlated variables in the later analyses, we conducted a correlation analysis and removed redundant climate variables. Spearman correlation between each diversity index and explanatory variable was used to assess pairwise relationships. Ordinary least squares models (OLSs) were applied to fit the relationship between each diversity index and all combinations of 1 or 2 explanatory variables. More complex models could not be fit with the available sample size. Model explanatory power was represented by adjusted $R^{2}$, while the small-sample-size corrected version of the Akaike Information Criterion $\left(\mathrm{AIC}_{\mathrm{c}}\right)$ was used to select the best model for each diversity index. The overall multi-model support for a given explanatory variable was estimated as the summed Akaike weights ( $w$, calculated by "importance" function) for all OLSs including this variable. We used Moran's $I$ test to check for spatial auto-correlation (SAC) in the residuals of all OLSs.

The statistical calculations were performed in R 2.15.1 ( $\mathrm{R}$ Development Core Team, 2010) using the packages picante (Kembel et al., 2010), spdep (Dormann et al., 2007), pscl (Jackman, 2010) and MuMIn (Barton, 2010).

\section{Results}

There were high correlations with groups of the environmental variables representing paleoclimate and representing current climate (Table A2). In the following, we therefore used MAT to represent current temperature (correlations between MAT and MTWM and MTCM were 0.69 and 0.98, respectively) and MAP to represent current precipitation (correlations between MAP and PWM and PDM were 0.96 and 0.93, respectively). The residuals of most of the OLSs had no spatial autocorrelation, except for a few weakly supported mod- els, so models accounting for spatial dependence were not implemented.

Considering bivariate rank correlations, functional community structure ( $\left.\mathrm{NRI}_{\mathrm{FUN}}\right)$ was only significantly correlated with proportion of light-demanding species (LDSR), no matter if species abundances were considered or not, and always so that functional clustering increased with increasing proportions of LDSR (Table 1). In contrast, phylogenetic structure (NRI $I_{P H Y}$ ) was significantly and positively correlated with the LGM-present MAT anomaly in most cases, i.e., phylogenetic clustering tended to increase with increasing late Quaternary temperature change. $\mathrm{NRI}_{\mathrm{PHY}}$ was also significantly correlated with current MAT and LGM-present MAT velocity in some cases, except for NRI PHY_gym_pr, which had no significant relations with any variables (Table 1).

Considering single-predictor OLSs, $\mathrm{NRI}_{\mathrm{FUN}}$ was also best explained by LDSR, while NRI $\mathrm{PHY}_{\mathrm{Y}}$ considering angiosperms was best explained by the LGM-present MAT anomaly and current MAT. Again, functional clustering increased with LDSR, while phylogenetic clustering increased with the increasing late Quaternary temperature shift. No significant relations were found for NRIPHY with gymnosperms included (Table 2, Fig. 2).

Considering both one- and two-predictor OLSs, LDSR had the strongest support for functional community structure, while the LGM-present MAT anomaly was the most important factor for NRI $\mathrm{NHY}_{\mathrm{PH}}$ considering only angiosperms (Table 3), and again with similar relations as indicated by the bivariate correlations and single-predictor OLSs. No particular variable was strongly supported for NRIPHY with gymnosperms included, although the LGM-present MAT anomaly was among the most supported (Table 3).

Tree and shrub communities showed different functional and phylogenetic patterns (Table 4). Generally, for NRIFUN the best and only important predictor was LDSR for trees and current MAP and MAT for shrubs. Although no significant relationships for growth-form-specific phylogenetic structure to any of the explanatory variables were found, the LGMpresent MAT anomaly again tended to be among the more important for phylogenetic structure of shrubs, but not for trees (Table 4).

\section{Discussion}

For woody plant communities in forests across China, phylogenetic and functional (as represented by variation in maximum canopy height) community structure show highly divergent relations to potential driving factors, with the former most-strongly constrained by paleoclimate and the latter most-strongly determined by contemporary local ecological dynamics. Hence, these two key aspects of woody plant diversity appear to be predominantly shaped by divergent assembly mechanisms, i.e., climatic niche conservation for 
Table 1. Spearman correlations $\left(r_{\mathrm{s}}\right)$ between each diversity index and each explanatory variable. NRI $\mathrm{FUN}_{\mathrm{N}}$ : functional $\left(H_{\mathrm{max}}\right)$ NRI, and NRI $I_{P H Y}$ : phylogenetic NRI, based on either presence-absence ( $\mathrm{pr}$ ) or abundances $\left({ }_{\mathrm{ab}}\right.$ ) with gymnosperms (gym) or only considering angiosperms (ang). Significant values are given in bold; ${ }^{*} p<0.05 ;{ }^{* *} p<0.01$.

\begin{tabular}{lrrrrrr}
\hline$r_{\text {S }}$ & Velocity & Anomaly & MAT & MAP & LDSR & Area \\
\hline NRI FUN_pr & 0.02 & -0.04 & 0.40 & 0.48 & $\mathbf{0 . 6 4}^{*}$ & -0.40 \\
NRI $_{\text {FUN_ab }}$ & 0.09 & 0.08 & 0.38 & 0.57 & $\mathbf{0 . 6 5}^{*}$ & -0.51 \\
NRIPHY_ang_pr & 0.57 & $\mathbf{0 . 7 2}^{*}$ & $-\mathbf{0 . 6 9}^{*}$ & -0.49 & -0.35 & 0.11 \\
NRIPHY_ang_ab & $\mathbf{0 . 6 1}^{*}$ & $\mathbf{0 . 8 2}^{* *}$ & $-\mathbf{0 . 6 6}^{*}$ & -0.32 & -0.38 & 0.05 \\
NRIPHY_gym_pr & 0.32 & 0.27 & -0.13 & -0.22 & -0.18 & 0.27 \\
NRIPHY_gym_ab & 0.45 & $\mathbf{0 . 6 5}^{*}$ & -0.16 & 0.35 & -0.03 & 0.34 \\
\hline
\end{tabular}

Table 2. Adjusted $R^{2}$ for single predictor OLSs of each diversity index against each explanatory variable. Significant values are given in bold; ${ }^{*} p<0.05 ;{ }^{* *} p<0.01$.

\begin{tabular}{lrrrrrr}
\hline & Velocity & Anomaly & MAT & MAP & LDSR & Area \\
\hline NRIFUN_pr & -0.11 & -0.10 & 0.13 & 0.26 & $\mathbf{0 . 6 2}^{* *}$ & -0.02 \\
NRI & -0.11 & -0.11 & 0.15 & $\mathbf{0 . 3 7}^{*}$ & $\mathbf{0 . 4 3}^{*}$ & -0.04 \\
NRI_PHYab & 0.11 & $\mathbf{0 . 3 8}^{*}$ & $\mathbf{0 . 5 5}^{* *}$ & 0.28 & 0.09 & -0.03 \\
NRI & 0.20 & $\mathbf{0 . 5 3}^{* *}$ & $\mathbf{0 . 3 4}^{*}$ & -0.02 & 0.02 & -0.08 \\
NRI_prang_ab & -0.04 & 0.03 & 0.00 & 0.04 & -0.03 & 0.06 \\
NRIPH_gym_pr & 0.15 & 0.20 & -0.11 & 0.03 & -0.09 & 0.07 \\
\hline
\end{tabular}

Table 3. Summed Akaike weights $(w)$ for each predictor variable based on all possible single- and two-predictor OLSs. Variables with $w \geq 0.50$ are given in bold.

\begin{tabular}{lrrrrrr}
\hline & Velocity & Anomaly & MAT & MAP & LDSR & Area \\
\hline NRI FUN_pr & 0.05 & 0.05 & 0.06 & 0.09 & $\mathbf{0 . 9 5}$ & 0.10 \\
NRI FUN_ab & 0.06 & 0.08 & 0.12 & 0.32 & $\mathbf{0 . 5 4}$ & 0.09 \\
NRIPHY_ang_pr & 0.06 & $\mathbf{0 . 5 2}$ & 0.45 & 0.46 & 0.06 & 0.06 \\
NRIPHY_ang_ab & 0.08 & $\mathbf{0 . 8 2}$ & 0.16 & 0.11 & 0.18 & 0.05 \\
NRIPHY_gym_pr & 0.11 & 0.15 & 0.13 & 0.16 & 0.11 & 0.19 \\
NRI & 0.21 & 0.33 & 0.12 & 0.17 & 0.08 & 0.15 \\
\hline
\end{tabular}

Table 4. Adjusted $R^{2}$ for single-predictor OLSs of each diversity index for the two functional groups (trees and shrubs) against each explanatory variable. Significant values are given in bold; ${ }^{*} p<0.05$.

\begin{tabular}{lrrrrrr}
\hline & Velocity & Anomaly & MAT & MAP & LDSR & Area \\
\hline NRI $_{\text {FUNTree_ab }}$ & -0.08 & 0.02 & -0.08 & -0.08 & 0.11 & -0.04 \\
NRI $_{\text {FUNShrub_ab }}$ & -0.11 & -0.09 & -0.08 & 0.03 & -0.06 & -0.11 \\
NRI FUNTree_pr $_{\text {FUN }}$ & -0.09 & -0.04 & -0.11 & -0.04 & $\mathbf{0 . 3 5}^{*}$ & -0.09 \\
NRIFUNShrub_pr & -0.07 & -0.05 & $\mathbf{0 . 3 2}^{*}$ & $\mathbf{0 . 3 7}$ & 0.04 & -0.11 \\
NRIPHY_ang Tree_ab & -0.09 & -0.03 & 0.00 & 0.17 & -0.08 & -0.03 \\
NRIPHY_angShrub_ab & 0.06 & 0.11 & 0.06 & -0.03 & 0.02 & -0.07 \\
NRIPHY_angTree_pr & -0.11 & -0.10 & -0.11 & -0.11 & 0.01 & 0.15 \\
NRIPHY_angShrub_pr & -0.03 & 0.13 & 0.01 & -0.11 & -0.03 & -0.08 \\
\hline
\end{tabular}



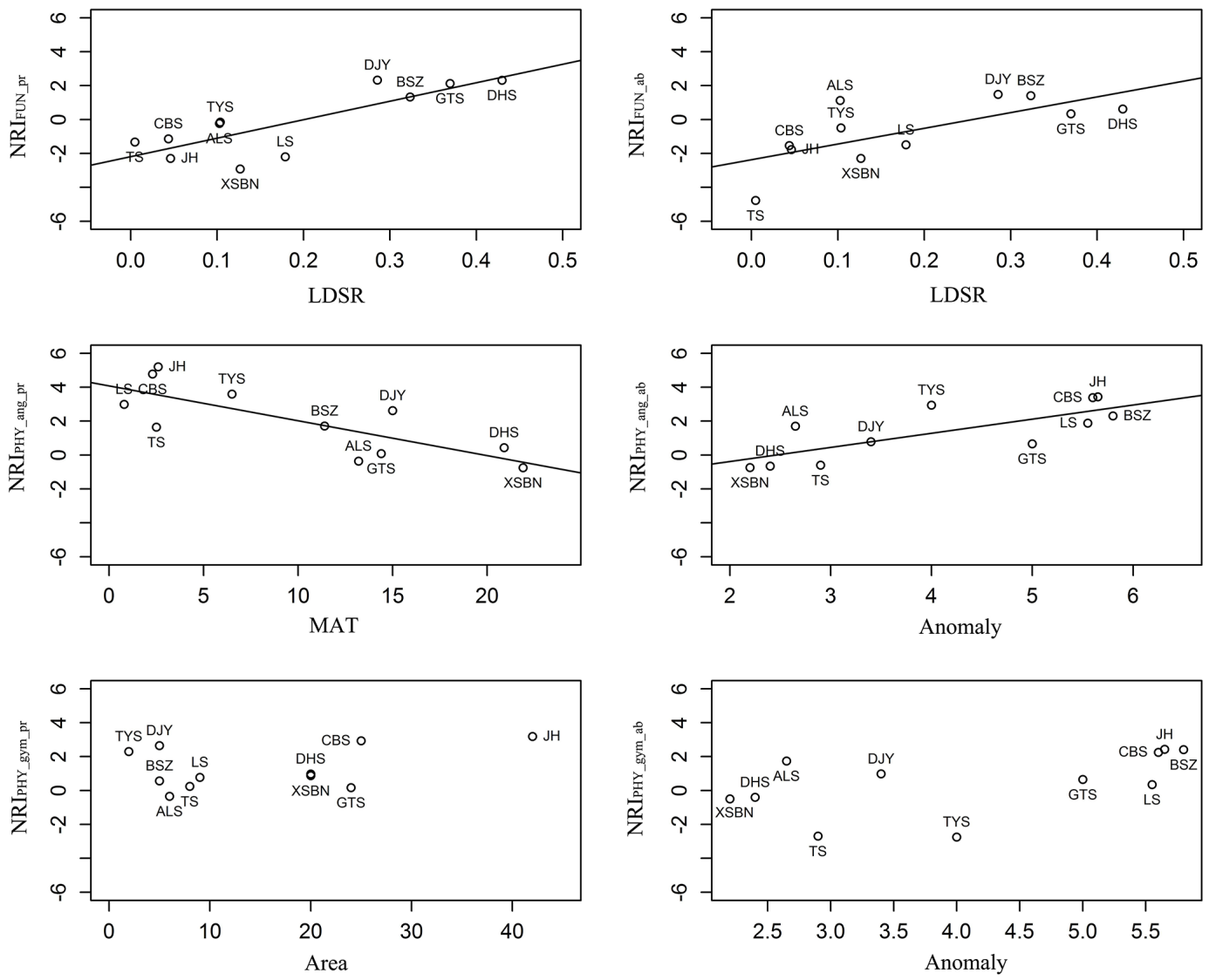

Fig. 2. Scatter plots of each diversity index against its best predictor. Linear regression fits are given for significant relationships. NRI $\mathrm{FUN}$ :

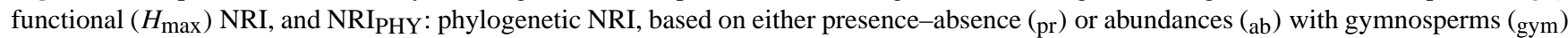
or only considering angiosperms (ang).

phylogenetic diversity and disturbance for functional diversity, acting on very different spatiotemporal scales. Growthform specific relations were generally weaker and less consistent, perhaps reflecting reduced species-wise sample sizes as well as growth-form specific dynamics.

Functional structure in this study was only represented by $H_{\max }$. Maximum canopy height is a key component of plant ecological strategies (Westoby, 1998), because it reflects the ability to compete for light, especially in dense, tall vegetation such as forests, and may also be correlated with other traits such as canopy area, leaf mass per area, leaf area ratio, metabolic rates, and dispersal ability (Enquist et al., 1998; Falster and Westoby, 2003; Moles et al., 2009; Thomson et al., 2011). Nevertheless, it is important to note that other aspects of functional diversity may very well show other geographic patterns and ecological relationships (Wright et al., 2007; Swenson and Weiser, 2010). In the present case, functional NRI was most correlated with the proportion of LDSR, an indicator of local-scale disturbance dynamics (Molino and Sabatier, 2001; Feng et al., 2014). In a smaller study area (8107 ha), Feng et al. (2014) also found LDSR to be well linked with functional diversity in a subtropical forest land- scape in southern China and concluded that this might reflect the important role of competition for light in determining forest structure. Across Chinese forests there was increasing functional clustering and thus decreasing variability in $H_{\max }$ with increasing LDSR. Notably, the standard deviation of $H_{\max }$ of the $30 \%$ most abundant species in the four plots with the highest LDSR was 7.6, while it was 10.8 in the four plots with the lowest LDSR, even after excluding the TS plot (with the lowest LDSR and the highest $H_{\max }$ standard deviation, 40.3) due to its low number of species $(n=8$ in total). Studies from other areas and vegetation types have also found functional clustering to increase with disturbance (Cianciaruso et al., 2012; Purschke et al., 2013).

A global study of plant height patterns showed that precipitation in the wettest month was the best predictor of height (Moles et al., 2009), which is partly consistent with our finding as the annual precipitation (highly correlated with the precipitation in the wettest month) was the second best predictor for $H_{\max }$-defined functional NRI. Furthermore, the trend towards increasing clustering with increasing temperature and precipitation (Table 1) also agreed with Moles et al. (2009) who found that cold, dry, and low productivity 
systems tended to have species with a wide range of height strategies, perhaps reflecting more shady conditions and increased competition for light under warm, wet conditions.

Long-term historical factors have been reported to be well correlated with various aspects of diversity at large geographic scales (Jansson, 2003; Kissling et al., 2012; Sandel et al., 2011; Rakotoarinivo et al., 2013). Notably, several studies have found the phylogenetic community structure to be strongly shaped by historical factors (Kissling et al., 2012). As a key example, Kissling et al. (2012) find that global patterns in phylogenetic structure for country-level palm assemblages is strongly linked to deep-time Cenozoic climate change, while there are also imprints of Quaternary climate change within some biogeographic regions. Notably, a strong increase in clustering with increasing LGM-present MAT anomaly is found within South America. Hortal et al. (2011) found a similar relation for scarab beetles within Europe, and a consistent pattern emerged for Chinese forest's woodyplant communities in the present study. Considering only angiosperms, we also found an increase phylogenetic clustering with the LGM-present MAT anomaly. Such a pattern may reflect strong filtering on phylogenetically conserved traits by the Pleistocene glaciations (Hortal et al., 2011). While eastern Asia was less affected by the Pleistocene glaciations than Europe or North America, these nevertheless caused massive vegetation changes and retraction of forests (Yu et al., 2000; Liu et al., 2003, 2013). The much weaker and often inconsistent patterns that resulted when gymnosperms were included probably reflect the potentially strong effects of such phylogenetic outlier groups on phylogenetic community structure (Letcher et al., 2012; Feng et al., 2014).

Tree and shrub communities showed substantially different patterns in terms of functional structure, which was in line with previous studies about species diversity (Wang et al., 2009a; Sandel et al., 2011) and further emphasized the importance of considering different taxonomic and functional groups regarding assembly mechanisms (Lindström and Langenheder, 2012). High correlation between LDSR and $H_{\max }$-defined functional NRI was only found in tree communities, while MAP was the best predictor of this measure for shrub communities. Wright (1992) argued that understory shrub diversity is critically affected by dry season rainfall, which may explain the particular importance of MAP for shrub functional NRI. For growth-form-specific phylogenetic structure, we did not find significant relations with any of the explanatory variables. The partially inconsistent and often weak relations for the growth-form-specific diversity measures may simply reflect the lower species-wise sample size for these subsets and thus greater sensitivity to stochastic processes.

Our study shows that functional (as represented by variation in maximum canopy height) and phylogenetic structure of woody-plant communities in Chinese forests are shaped by divergent processes, i.e., climatic niche conservation for phylogenetic diversity and disturbance for functional diver- sity, acting on very different spatiotemporal scales. Functional structure was more determined by contemporary local dynamics, while paleoclimate was more important for phylogenetic structure. These differences are consistent with theoretical expectations, i.e., phylogenetic patterns reflect biogeography history and functional structure reflect ongoing ecological processes, and the few existing empirical studies (Kissling et al., 2012; Purschke et al., 2013), pointing to their potential wider generality. Many further studies will be needed for assessing this. Furthermore, functional diversity in the present study was represented by a single - albeit very important - functional trait, namely, maximum canopy height. Other aspects of functional diversity may well reflect different determining factors, e.g., interactions among traits or climate (Wright et al., 2007; Swenson and Weiser, 2010). As both phylogenetic structure and functional traits may affect forest ecosystem functioning and ecosystem services, our findings illustrate that these may be shaped by both local contemporary and long-term regional processes.

\section{Supplementary material related to this article is available online at http://www.biogeosciences.net/11/ 1361/2014/bg-11-1361-2014-supplement.zip.}

Acknowledgements. We thank Bingyang Ding for support of using data from the Baishanzu plot, Mide Rao for the improvement of the draft and Dongmei Jin for the help of building the phylogeny trees. We are grateful for economic support from the Chinese Scholarship Council (file no. 201204910187 to G. Feng), the European Research Council (grant ERC-2012-StG-310886-HISTFUNC to J.-C. Svenning) and the Danish Council for Independent Research | Natural Sciences (grant 12-125079 to J.-C. Svenning).

Edited by: K. Thonicke

\section{References}

Angiosperm Phylogeny Group III.: An update of the Angiosperm Phylogeny Group classification for the orders and families of flowering plants: APG III, Bot. J. Linn. Soc., 161, 105-121, 2009.

Barton, K.: MuMIn: Multi-model inference R package [version 01317], 2010.

Bivand, R.: spdep: spatial dependence: weighting schemes, statistics and models, 2007.

Chen, L., Mi, X., Comita, L. S., Zhang, L., Ren, H., and Ma, K.: Community-level consequences of density dependence and habitat association in a subtropical broad-leaved forest, Ecol. Lett., 13, 695-704, 2010.

Chesson, P.: Mechanisms of maintenance of species diversity, Annu. Rev. Ecol. Syst., 31, 343-366, 2000.

Cianciaruso, M. V., Silva, I. A., Batalha, M. A., Gaston, K. J., and Petchey, O. L.: The influence of fire on phylogenetic and func- 
tional structure of woody savannas: moving from species to individuals, Perspect. Plant Ecol., 14, 205-216, 2012.

Collins, W. D., Bitz, C. M., Blackmon, M. L., Bonan, G. B., Bretherton, C. S., Carton, J. A., Chang, P., Doney, S. C., Hack, J. J., Henderson, T. B., Kiehl, J. T., Large, W. G., McKenna, D. S., Santer, B. D., and Smith, R. D.: The Community Climate System Model Version 3 (CCSM3), J. Climate, 19, 2122-2143, 2006.

De Aguiar, M. A. M., Baranger, M., Baptestini, E. M., Kaufman, L., and Bar-Yam, Y.: Global patterns of speciation and diversity, Nature, 460, 384-387, 2009.

Dynesius, M. and Jansson, R.: Evolutionary consequences of changes in species' geographical distributions driven by Milankovitch climate oscillations, P. Natl. Acad. Sci. USA, 97, 9115-9120, 2000.

Enquist, B. J., Brown, J. H., and West, G. B.: Allometric scaling of plant energetics and population density, Nature, 395, 163-165, 1998.

Falster, D. S. and Westoby, M.: Plant height and evolutionary games, Trends Ecol. Evol., 18, 337-343, 2003.

Feng, G., Svenning, J. C., Mi, X.C., Jia, Q., Rao, M. D., Ren, H. B., Bebber, D. P., and Ma, K. P.: Anthropogenic disturbance shapes phylogenetic and functional tree community structure in a subtropical forest, Forest Ecol. Manag., 313, 188-198, 2014.

Greve, M., Lykke, A. M., Blach-Overgaard, A., and Svenning, J. C.: Environmental and anthropogenic determinants of vegetation distribution across Africa, Global Ecol. Biogeogr., 20, 661-674, 2011

Hijmans, R. J., Cameron, S. E., Parra, J. L., Jones, P. G., and Jarvis, A.: Very high resolution interpolated climate surfaces for global land areas, Int. J. Climatol., 25, 1965-1978, 2005.

Hortal, J., Diniz-Filho, J. A. F., Bini, L. M., Rodríguez, M. Á., Baselga, A., Nogués-Bravo, D., Rangel, T. F., Hawkins, B. A., and Lobo, J. M.: Ice age climate, evolutionary constraints and diversity patterns of European dung beetles, Ecol. Lett., 14, 741748,2011

Jackman, S.: pscl: classes and methods for R developed in the political science computational laboratory: Stanford University, Stanford, CA, Department of Political Science, Stanford University, 2010.

Jansson, R.: Global patterns in endemism explained by past climatic change, P. Roy. Soc. B-Biol. Sci., 270, 583-590, 2003.

K-1 Model Developers.: K-1 coupled model (MIROC) description, edited by H. Hasumi and S. Emori, K-1 Tech. Rep. 1, 34 pp., Center for Climate System Research, University of Tokyo, 2004.

Kellermann, V., Loeschcke, V., Hoffmann, A. A., Kristensen, T. N., Fløjgaard, C., David, J. R., Svenning, J. C., and Overgaard, J.: Phylogenetic constraints in key functional traits behind species'climate niches: patterns of desiccation and cold resistance across 95 drosophila species, Evolution, 66, 3377-3389, 2012a.

Kellermann, V., Overgaard, J., Hoffmann, A. A., Fløjgaard, C., Svenning, J.-C., and Loeschcke, V.: Upper thermal limits of Drosophila are linked to species distributions and strongly constrained phylogenetically, P. Natl. Acad. Sci. USA, 109, 1622816233, 2012b.

Kembel, S. W., Cowan, P. D., Helmus, M. R., Cornwell, W. K., Morlon, H., Ackerly, D. D., Blomberg, S. P., and Webb, C. O.: Picante: R tools for integrating phylogenies and ecology, Bioinformatics, 26, 1463-1464, 2010.
Kissling, W. D., Eiserhardt, W. L., Baker, W. J., Borchsenius, F., Couvreur, T. L., Balslev, H., and Svenning, J.-C.: Cenozoic imprints on the phylogenetic structure of palm species assemblages worldwide, P. Natl. Acad. Sci. USA, 109, 7379-7384, 2012.

Kunstler, G., Lavergne, S., Courbaud, B., Thuiller, W., Vieilledent, G., Zimmermann, N. E., Kattge, J., and Coomes, D. A.: Competitive interactions between forest trees are driven by species' trait hierarchy, not phylogenetic or functional similarity: implications for forest community assembly, Ecol. Lett., 15, 831-840, 2012.

Latham, R. E. and Ricklefs, R. E.: Global patterns of tree species richness in moist forests: energy-diversity theory does not account for variation in species richness, Oikos, 67, 325-333, 1993.

Letcher, S. G., Chazdon, R. L., Andrade, A., Bongers, F., van Breugel, M., Finegan, B., Laurance, S. G., Mesquita, R. C., Martínez-Ramos, M., and Williamson, G. B.: Phylogenetic community structure during succession: evidence from three Neotropical forest sites, Perspect. Plant Ecol., 14, 79-87, 2012.

Lindström, E. S. and Langenheder, S.: Local and regional factors influencing bacterial community assembly, Environ. Microbiol. Reports, 4, 1-9, 2012.

Liu, H., Xing, Q., Ji, Z., Xu, L., and Tian, Y.: An outline of Quaternary development of Fagus forest in China: palynological and ecological perspectives, Flora, 198, 249-259, 2003.

Liu, L., Bestel, S., Shi, J., Song, Y., and Chen, X.: Paleolithic human exploitation of plant foods during the last glacial maximum in North China, P. Natl. Acad. Sci. USA, 110, 5380-5385, 2013.

Loarie, S. R., Duffy, P. B., Hamilton, H., Asner, G. P., Field, C. B., and Ackerly, D. D.: The velocity of climate change, Nature, 462, 1052-1055, 2009.

López-Pujol, J., Zhang, F.-M., and Ge, S.: Plant biodiversity in China: richly varied, endangered, and in need of conservation, Biodivers Conserv, 15, 3983-4026, 2006.

Losos, J. B.: Phylogenetic niche conservatism, phylogenetic signal and the relationship between phylogenetic relatedness and ecological similarity among species, Ecol. Lett., 11, 995-1003, 2008.

Mi, X., Swenson, N. G., Valencia, R., Kress, W. J., Erickson, D. L., Pérez, A. J., Ren, H., Su, S.-H., Gunatilleke, N., and Gunatilleke, S.: The contribution of rare species to community phylogenetic diversity across a global network of forest plots, Am. Nat., 180, E17-E30, 2012.

Moles, A. T., Warton, D. I., Warman, L., Swenson, N. G., Laffan, S. W., Zanne, A. E., Pitman, A., Hemmings, F. A., and Leishman, M. R.: Global patterns in plant height, J. Ecol., 97, 923932, 2009.

Molino, J. F. and Sabatier, D.: Tree diversity in tropical rain forests: A validation of the intermediate disturbance hypothesis, Science, 294, 1702-1704, 2001.

Pennisi, E.: What determines species diversity, Science, 309, 90-90, 2005.

Purschke, O., Schmid, B. C., Sykes, M. T., Poschlod, P., Michalski, S. G., Durka, W., Kühn, I., Winter, M., and Prentice, H. C.: Contrasting changes in taxonomic, phylogenetic and functional diversity during a long-term succession: insights into assembly processes, J. Ecol., 101, 857-866, 2013.

Qian, H. and Ricklefs, R. E.: A comparison of the taxonomic richness of vascular plants in China and the United States, Am. Nat. 154, 160-181, 1999. 
Qian, H. and Ricklefs, R. E.: Large-scale processes and the Asian bias in species diversity of temperate plants, Nature, 407, 180$182,2000$.

R Development Core Team.: R: a language and environment for statistical computing, Vienna, R Foundation for Statistical Computing, 2010.

Rakotoarinivo, M., Blach-Overgaard, A., Baker, W. J., Dransfield, J., Moat, J., and Svenning, J.-C.: Palaeo-precipitation is a major determinant of palm species richness patterns across Madagascar: a tropical biodiversity hotspot, P. Roy. Soc. B-Biol. Sci., 280, 20123048, doi:10.1098/rspb.2012.3048, 2013.

Ricklefs, R. E.: Community diversity: relative roles of local and regional processes, Science, 235, 167-171, 1987.

Ricklefs, R. E., Latham, R. E., and Qian, H.: Global patterns of tree species richness in moist forests: distinguishing ecological influences and historical contingency, Oikos, 86, 369-373, 1999.

Sandel, B., Arge, L., Dalsgaard, B., Davies, R., Gaston, K., Sutherland, W., and Svenning, J.-C.: The influence of Late Quaternary climate-change velocity on species endemism, Science, 334, 660-664, 2011.

Smith, S. E., Gregory, R. D., Anderson, B. J., and Thomas, C. D.: The past, present and potential future distributions of coldadapted bird species, Divers. Distrib., 19, 352-362, 2013.

Svenning, J.-C., Kinner, D. A., Stallard, R. F., Engelbrecht, B. M. J., and Wright, S. J.: Ecological determinism in plant community structure across a tropical forest landscape, Ecology, 85, 25262538, 2004.

Swenson, N. G.: Phylogenetic resolution and quantifying the phylogenetic diversity and dispersion of communities, Plos One, 4, e4390, doi:10.1371/journal.pone.0004390, 2009.

Swenson, N. G.: The assembly of tropical tree communities-the advances and shortcomings of phylogenetic and functional trait analyses, Ecography, 36, 264-276, 2013.

Swenson, N. G. and Enquist, B. J.: Opposing assembly mechanisms in a Neotropical dry forest: implications for phylogenetic and functional community ecology, Ecology, 90, 2161-2170, 2009.

Swenson, N. G. and Weiser, M. D.: Plant geography upon the basis of functional traits: an example from eastern North American trees, Ecology, 91, 2234-2241, 2010.
Thomson, F. J., Moles, A. T., Auld, T. D., and Kingsford, R. T.: Seed dispersal distance is more strongly correlated with plant height than with seed mass, J. Ecol., 99, 1299-1307, 2011.

Tittensor, D. P., Mora, C., Jetz, W., Lotze, H. K., Ricard, D., Vanden Berghe, E., and Worm, B.: Global patterns and predictors of marine biodiversity across taxa, Nature, 466, 1098-U1107, 2010.

Wang, X., Fang, J., Sanders, N. J., White, P. S., and Tang, Z.: Relative importance of climate vs local factors in shaping the regional patterns of forest plant richness across northeast China, Ecography, 32, 133-142, 2009a.

Wang, X., Wiegand, T., Wolf, A., Howe, R., Davies, S. J., and Hao, Z.: Spatial patterns of tree species richness in two temperate forests, J. Ecol., 99, 1382-1393, 2011.

Wang, Z., Brown, J. H., Tang, Z., and Fang, J.: Temperature dependence, spatial scale, and tree species diversity in eastern Asia and North America, P. Natl. Acad. Sci. USA, 106, 13388-13392, 2009b.

Webb, C. O., Ackerly, D. D., McPeek, M. A., and Donoghue, M. J.: Phylogenies and community ecology, Annu. Rev. Ecol. Syst., 33, 475-505, 2002.

Webb, C. O., Ackerly, D. D., and Kembel, S. W.: Phylocom: software for the analysis of phylogenetic community structure and trait evolution, Bioinformatics, 24, 2098-2100, 2008.

Westoby, M.: A leaf-height-seed (LHS) plant ecology strategy scheme, Plant Soil, 199, 213-227, 1998.

Wiens, J. J. and Graham, C. H.: Niche conservatism: integrating evolution, ecology, and conservation biology, Annu. Rev. Ecol. Evol. S., 36, 519-539, 2005.

Wright, I. J., Ackerly, D. D., Bongers, F., Harms, K. E., IbarraManriquez, G., Martinez-Ramos, M., Mazer, S. J., MullerLandau, H. C., Paz, H., and Pitman, N. C.: Relationships among ecologically important dimensions of plant trait variation in seven Neotropical forests, Ann. Bot., 99, 1003-1015, 2007.

Yu, G., Chen, X., Ni, J., Cheddadi, R., Guiot, J., Han, H., Harrison, S. P., Huang, C., Ke, M., and Kong, Z.: Palaeovegetation of China: a pollen data-based synthesis for the mid-Holocene and last glacial maximum, J. Biogeogr., 27, 635-664, 2000.

Zhu, Y., Mi, X., Ren, H., and Ma, K.: Density dependence is prevalent in a heterogeneous subtropical forest, Oikos, 119, 109-119, 2010 . 


\section{Appendix A}

Table A1. General information of 11 forest plots in China. No.species: number of species in each plot. Anomaly: LGM-present MAT anomaly. MAT: mean annual temperature. MAP: mean annual precipitation. LDSR: proportion of light demanding species. NRI $\mathrm{FUN}_{\mathrm{N}}$ : functional $\left(H_{\mathrm{max}}\right)$ NRI, and NRI $\mathrm{PHY}_{\mathrm{Y}}$ : phylogenetic NRI, both based on either presence-absence ( $\mathrm{pr}$ ) or abundances $(\mathrm{ab})$ with gymnosperms (gym) or only considering angiosperms (ang).

\begin{tabular}{|c|c|c|c|c|c|c|c|c|c|c|c|}
\hline & ALS & BSZ & CBS & DHS & DJY & GTS & $\mathrm{JH}$ & $\mathrm{LS}$ & TS & TYS & $\mathrm{XSBN}$ \\
\hline No. species & 68 & 152 & 50 & 198 & 98 & 158 & 48 & 45 & 8 & 21 & 342 \\
\hline Longitude & 101.03 & 119.2 & 128.08 & 112.54 & 103.45 & 118.12 & 127.74 & 128.89 & 87.47 & 112.15 & 101.58 \\
\hline Latitude & 24.54 & 27.76 & 42.38 & 23.17 & 30.73 & 29.25 & 43.96 & 47.18 & 43.43 & 36.69 & 21.61 \\
\hline Area (ha) & 6 & 5 & 25 & 20 & 5 & 24 & 42 & 9 & 8 & 1.96 & 20 \\
\hline Velocity & 0.3 & 2.23 & 4.35 & 0.63 & 0.58 & 1.88 & 0.85 & 2.28 & 0.27 & 0.67 & 0.39 \\
\hline Anomaly & 2.65 & 5.8 & 5.6 & 2.4 & 3.4 & 5 & 5.65 & 5.55 & 2.9 & 4 & 2.2 \\
\hline MAT & 13.2 & 11.4 & 2.3 & 20.9 & 15 & 14.4 & 2.6 & 0.8 & 2.5 & 6.5 & 21.9 \\
\hline MAP (mm year $\left.{ }^{-1}\right)$ & 1116 & 2147 & 693 & 1698 & 1202 & 1935 & 671 & 648 & 239 & 588 & 1575 \\
\hline LDSR & 0.1 & 0.32 & 0.04 & 0.43 & 0.29 & 0.37 & 0.05 & 0.18 & 0 & 0.1 & 0.13 \\
\hline NRI FUN_pr & -0.23 & 1.33 & -1.13 & 2.32 & 2.33 & 2.13 & -2.29 & -2.19 & -1.32 & -0.15 & -2.92 \\
\hline NRI FUN_ab & 1.12 & 1.41 & -1.54 & 0.62 & 1.48 & 0.34 & -1.77 & -1.49 & -4.78 & -0.5 & -2.29 \\
\hline NRIPHY_ang_pr & -0.36 & 1.71 & 4.77 & 0.43 & 2.62 & 0.08 & 5.2 & 2.99 & 1.64 & 3.6 & -0.75 \\
\hline NRIPHY_ang_ab & 1.7 & 2.3 & 3.38 & -0.66 & 0.79 & 0.66 & 3.44 & 1.88 & -0.6 & 2.94 & -0.74 \\
\hline NRIPHY_gym_pr & -0.34 & 0.56 & 2.93 & 0.98 & 2.65 & 0.17 & 3.19 & 0.78 & 0.24 & 2.3 & 0.87 \\
\hline NRI PHY_gym_ab & 1.74 & 2.41 & 2.25 & -0.4 & 0.98 & 0.65 & 2.43 & 0.35 & -2.69 & -2.75 & -0.49 \\
\hline
\end{tabular}

Table A2. Matrix of correlation coefficients (CorCoe)among the 10 environmental variables. The bold value in each column indicates the most correlated variable within that column.

\begin{tabular}{lrrrrrrrrrr}
\hline CorCoe & Velocity & Anomaly & MAT & MAP & MTWM & MTCM & PWM & PDM & LDSR & Area \\
\hline Velocity & 1 & $\mathbf{0 . 7 4}$ & -0.42 & 0.03 & -0.17 & -0.44 & 0.02 & 0.12 & 0 & 0.21 \\
Anomaly & $\mathbf{0 . 7 4}$ & 1 & -0.63 & -0.04 & -0.32 & -0.64 & -0.02 & 0.1 & -0.03 & 0.29 \\
MAT & -0.42 & -0.63 & 1 & 0.76 & $\mathbf{0 . 6 9}$ & $\mathbf{0 . 9 8}$ & 0.77 & 0.58 & 0.63 & -0.1 \\
MAP & 0.03 & -0.04 & 0.76 & 1 & 0.5 & 0.77 & $\mathbf{0 . 9 6}$ & $\mathbf{0 . 9 3}$ & $\mathbf{0 . 8 2}$ & 0.01 \\
MTWM & -0.17 & -0.32 & 0.69 & 0.5 & 1 & 0.55 & 0.52 & 0.4 & 0.6 & $\mathbf{0 . 3 3}$ \\
MTCM & -0.44 & -0.64 & $\mathbf{0 . 9 8}$ & 0.77 & 0.55 & 1 & 0.76 & 0.61 & 0.62 & -0.2 \\
PWM & 0.02 & -0.02 & 0.77 & $\mathbf{0 . 9 6}$ & 0.52 & 0.76 & 1 & 0.82 & 0.79 & 0.03 \\
PDM & 0.12 & 0.1 & 0.58 & 0.93 & 0.4 & 0.61 & 0.82 & 1 & 0.79 & 0.07 \\
LDSR & 0 & -0.03 & 0.63 & 0.82 & 0.6 & 0.62 & 0.79 & 0.79 & 1 & -0.1 \\
Area & 0.21 & 0.29 & -0.07 & 0.01 & 0.33 & -0.2 & 0.03 & 0.07 & -0.1 & 1 \\
\hline
\end{tabular}

